\title{
A Simple and Sensitive High Performance Liquid Chromatography-Electrospray Ionization/Mass Spectrometry Method for the Quantification of Ethyl Pyruvate in Rat Plasma
}

\author{
Hyun-Ji Kim, Seung-Woo Kim, ${ }^{\dagger}$ Ja-Kyeong Lee, ${ }^{\dagger}$ and Sung-Hwa Yoon ${ }^{*}$ \\ Department of Molecular Science and Technology, Ajou University, Suwon 443-749, Korea. *E-mail: shyoon@ajou.ac.kr \\ ${ }^{\dagger}$ Department of Anatomy, Center for Advanced Medical Education, School of Medicine, Inha University, Inchon 400-712, Korea \\ Received September 10, 2010, Accepted February 7, 2011
}

\begin{abstract}
Ethyl pyruvate (EP) is known as a scavenger of reactive oxygen species (ROS) in the body through its role in the donation of diketone groups to metals to form an EP-metal complex. In order to develop a method for the quantification of EP in biological media, a sensitive and specific, high-performance liquid chromatographyelectrospray ionization-mass spectrometry (HPLC-ESI/MS) method is used to determine the EP-alkali metal ion binding species. The analyte was separated on a ZORBOX SB-C8 (3.5 $\mu \mathrm{m}, 30 \mathrm{~mm} \times 2.1 \mathrm{~mm}$ I.D. $)$ column and analyzed in selected ion monitoring (SIM) mode with a positive ESI interface using the $m / z 255$ [2M + $\mathrm{Na}^{+}$ion. The method was validated over the concentration range of $0.5-60.0 \mu \mathrm{g} / \mathrm{mL}$ under $1 / 9(\mathrm{v} / \mathrm{v})$ of acetonitrile/methanol solvent system with flow rate $0.05 \mathrm{~mL} / \mathrm{min}$. The limit of quantification (LOQ) was 0.5 $\mu \mathrm{g} / \mathrm{mL}$
\end{abstract}

Key Words : Ethyl pyruvate, Quantification, Liquid chromatography-mass spectrometry, Electrospray ionization, Sodium adduct formation

\section{Introduction}

Ethyl pyruvate (EP) is a simple lipophilic derivative of pyruvic acid that is the endogenous metabolite of glucose, and is currently used as an artificial ingredient. As a scavenger of reactive oxygen species (ROS), EP has exhibited protective effects against oxidative stress or a relationship with various ROS-mediated diseases. For example, EP exerts protective effects against oxidative stress-mediated cellular injury, ${ }^{1}$ mesenteric injury, ${ }^{2,3}$ myocardial injury, ${ }^{4}$ intestinal injury, ${ }^{5}$ hepatic injury, ${ }^{6}$ ischemia/reperfusion-induced epithelial injury, ${ }^{7}$ hemorrhagic shock, ${ }^{8}$ lethal sepsis and systemic inflammation, ${ }^{9}$ superfused neonatal cerebrocortical slices after $\mathrm{H}_{2} \mathrm{O}_{2}$ stress, ${ }^{10}$ high mobility group box 1 secretion in chronic inflammation, ${ }^{11}$ hepatic tumor growth, ${ }^{12}$ inflammatory function by inhibiting signaling via the NF- $\kappa \mathrm{B}$ pathway, ${ }^{13}$ pressure-induced retinal damage, ${ }^{14}$ ameliorate ${ }^{15}$ and damage to the lens of the eye caused by oxidants. ${ }^{16}$ Recently, we also reported that EP exerted a neuroprotective effect with the remarkable suppression of hippocampal cell death in a murine kainic acid-induced epilepsy mode ${ }^{17}$ and with reduced infarct volume and suppressed the clinical manifestations, including motor impairment and neurological deficits, in postischemic rat brain. ${ }^{18}$

Despite these interesting biological effects of EP, surprisingly, there is no report regarding the quantification of EP in biological media. To the best of our knowledge, two methods have been reported for the determination of EP. Shimizu group used gas chromatography-MS (GC-MS) to detect EP in beer. ${ }^{19}$ Their method was adequate for determining EP in aqueous media, but it didn't quantify EP concentration in biological media. In another method, Bartók et al. reported the method in which the intermediate complex of EP and the organic compounds in the chiral reactions was detected by electrospray ionization mass spectrometry (ESI/MS) after EP was induced by organic compounds such as dihydrocinchonidine, ${ }^{20}$ acetic anhydride and pyridine, ${ }^{21}$ and acetylpyridinium. ${ }^{22}$ Although this method was useful for elucidating the mechanism and intermediates of the heterogeneous catalytic asymmetric reactions of pyruvates containing $\alpha$-diketo unit, unfortunately, it is not suitable for the quantification of low concentrations of EP in biological media because the signals corresponding to doubly and triply sodiated molecular ions as well as the adducts formed by the catalyst, $\mathrm{Pt} / \mathrm{Al}_{2} \mathrm{O}_{3}$, a modifier, and dihydrocinchonidine (DHCD) displayed the complicated 26 different peaks in the mass spectra. Moreover, Bartók's method did not provide any HPLC condition which is inevitable for the quantification of EP in biological media. Therefore, we need to develop and validate an assay for quantifying EP in biological media with appropriate sensitivity, accuracy and precision along with the simple extraction and protein precipitation method for determining EP concentrations in the biological sample.

In this article, we describe a method for quantifying EP with simplicity and precision using high performance liquid chromatography-electrospray ionization/mass spectrometry (HPLC-ESI/MS) in rat plasma with limit of quantitative (LOQ) of $0.5 \mu \mathrm{g} / \mathrm{mL}$ for $0.2 \mathrm{~mL}$ plasma. The method was successfully applied to the pharmacokinetics study of $\mathrm{EP}$ in rats after a single intravenous injection of $50 \mathrm{mg} / \mathrm{kg}$ concentration in the tail vein. 


\section{Experimental}

Chemicals. EP was purchased from Sigma-Aldrich Chemie (USA). Methanol and acetonitrile of HPLC grade were purchased from J. T. Baker (Phillipsburg, USA). Water was purified by redistillation and filtered through a C18 Empore filter (3M, USA) before use.

Instrument and Analytical Conditions. LCMS 2010EV LC-MS instrument (Chiyoda-Ku, Tokyo, Japan) equipped with an ESI (Ed- this acronym has already been defined above) probe and Q-array-octapole-quadrupole (QoQ) mass analyzer was used. The chromatographic system consisted of an LC-20AD pump, a DGU-20A3 degasser, a Shimadzu SIL-20A autosampler, a CTO-20A column oven and a SPDM20A UV/vis photodiode array detector. The column [ZORBAX SB-C8, $30 \mathrm{~mm} \times 2.1 \mathrm{~mm}$ i.d.; packed with C8 silica; particle size $3.5 \mu \mathrm{m}$ ] was purchased from Agilent (USA). Chromatography was carried out in isocratic mode with a 100/0, 80/20, 60/40, 40/60, 30/70, 20/80, 10/90, and $0 / 100$ mixture of acetonitrile and methanol at a flow rate of $0.05 \mathrm{~mL} / \mathrm{min}$. The analyses were performed with the column maintained at $30.0{ }^{\circ} \mathrm{C}$ and $10.0 \mu \mathrm{L}$ was injected for each analysis. The effluent from the UV detector was introduced into the mass spectrometer without any splitting of the flow.

Mass Spectrometry (MS). The analyte was determined in the positive ESI mode. MS conditions were optimized to obtain maximum sensitivity. Quantification was performed by MS method using selected ion monitoring (SIM) of the product. The curve dissolution line temperature was $250{ }^{\circ} \mathrm{C}$ and the block temperature was $200^{\circ} \mathrm{C}$. The heated capillary temperature was maintained at $200{ }^{\circ} \mathrm{C}$. The detector voltage was set at $1.5 \mathrm{kV}$ and the probe voltage at $4.5 \mathrm{kV}$. The mass spectrometer was equipped with Edwards E2M28 two stage rotary vacuum pumps (Edwards, UK). Nitrogen was used as nebulizing and drying gas at $1.5 \mathrm{~L} / \mathrm{min}$ and $12 \mathrm{~L} / \mathrm{min}$, respectively. LC/MS Solution Version 3.3 working on a Windows XP operating system was used for data processing.

Standard Solutions. The primary stock solutions of EP were prepared by dissolving $10.0 \mathrm{mg}$ in $10 \mathrm{~mL}$ acetonitrile, and were stored at $-20{ }^{\circ} \mathrm{C}$ until analysis. After working solutions of the analytes were prepared by appropriate dilution of the primary stock solutions in acetonitrile, $10 \mu \mathrm{L}$ of EP working solutions were spiked into $190 \mu \mathrm{L}$ blank rat plasma in an Eppendorf $1.5 \mathrm{~mL}$ microcentrifuge polypropylene tube to make a calibration standard curve. The final concentrations of EP were as follows: 0.1, 0.5, 1.0, 5.0, 10.0, $20.0,40.0$ and $60.0 \mu \mathrm{g} / \mathrm{mL}$. The quality control (QC) samples were prepared at the beginning of the project initialization by adding $100 \mu \mathrm{L}$ of $\mathrm{EP}$ working solution to $1.9 \mathrm{~mL}$ rat plasma for homogenization. The QC samples were divided into $200 \mu \mathrm{L}$ and stored at $-20{ }^{\circ} \mathrm{C}$ in Eppendorf $1.5 \mathrm{~mL}$ microcentrifuge polypropylene tubes. Only one tube of QC standard at each concentration level was taken out to be melted for use in each run. $N, N$-Dimethylacetamide (DMA) was used as the internal standard (IS). The initial stock solution was prepared by dissolving $10.0 \mathrm{mg}$ of DMA in 10 $\mathrm{mL}$ acetonitrile to produce a primary stock solution, and the final DMA concentration was $20.0 \mu \mathrm{g} / \mathrm{mL}$. The diluted standard and IS solutions were prepared freshly before use.

Plasma Sample Preparation. A $200 \mu \mathrm{L}$ volume of rat plasma was transferred to an Eppendorf tube and was mixed with $20 \mu \mathrm{L}$ (40 ng) of IS working solution and $200 \mu \mathrm{L}$ of acetonitrile. The mixture was vortexed for $1 \mathrm{~min}$ using a MS1 Minishaker (IKA works (Asia) Sdn. Bhd.), centrifuged using VS-15000 (Brushless D.C motor centrifuge) for 15 min at $5000 \mathrm{rpm}$, and filtered through a nylon syringe filter (0.2 $\mu \mathrm{m}$ pore size, Whatman, Schleicher \& Schuell). The supernatant was transferred to an auto-sampler micro vial, stored at $-20{ }^{\circ} \mathrm{C}$, and an aliquot of $10 \mu \mathrm{L}$ was injected into the HPLC-ESI/MS system for analysis.

Calibration Curve. The calibration curve was obtained by spiking the control with $100.0 \mu \mathrm{g} / \mathrm{mL}$ of the stock solution. The concentrations of the spiked analytes in solution were $0.1,0.5,1.0,5.0,10.0,20.0,40.0$ and $60.0 \mu \mathrm{g} / \mathrm{mL}$. The calibration curve was made from the relative peak intensities of EP. The calibration curve was established by fitting the corresponding nominal concentrations by a linear regression method. The limit of quantification (LOQ) and the limit of detection (LOD) were considered to be the concentrations that produced a signal-to-noise $(\mathrm{S} / \mathrm{N})$ ratio of $5 / 1$ and $3 / 1$, respectively. For quantification of EP the $m / z 255$ and SIM mode were used. The quality control (QC) samples that were run in each assay at concentrations of 10.0 and $40.0 \mu \mathrm{g} / \mathrm{mL}$ were also prepared.

Pharmacokinetics Study. A study was designed to investigate the pharmacokinetics of EP in adult male SpragueDawley rats. Sprague-Dawley rats approximately 6-8 weeks of age (mass $=250-300 \mathrm{~g}$ ) were administered a $50 \mathrm{mg} / \mathrm{kg}$ intravenous (i.v.) bolus dose via the tail vein. For intravenous bolus, EP was first dissolved in distilled water, and the dosing solution was delivered using a $1 \mathrm{~mL}$ syringe into the rat's tail vein. The sample preparations were made immediately before drug administration. Blood samples were collected from the heart and stored in a heparin-containing tube before dosing and at $5,10,15,30,60$, and 120 min post dosing. After the blood samples were centrifuged, the plasma samples were collected and stored at $-20^{\circ} \mathrm{C}$ until analysis.

Statistical Analysis. Statistical analyses were performed by SigmaPlot 8.0 . All data were presented as the average \pm SEM, and statistical significance was set at the 5\% level.

\section{Results and Discussion}

Determination of EP in Acetonitrile. We initially tried to detect the ionized form $[\mathrm{M}+\mathrm{H}]^{+}$of EP in the organic solvent. However, EP containing an $\alpha$-ketoester group did not generate the ionized form $[\mathrm{M}+\mathrm{H}]^{+}$or $[\mathrm{M}-\mathrm{H}]^{-}$under a general HPLC-MS/ESI positive or negative condition. ${ }^{23}$ This finding can be explained by the following result reported by Sheryl et al. Compound (L) containing basic functional groups generally generates the molecular mass as an adduct of alkali cation metals, such as $\mathrm{Na}^{+}$or $\mathrm{K}^{+}$, due to the weaker oxygen bases. ${ }^{24,25}$ This chelation with alkali metal cation and solvent molecules leads to the formation of the 


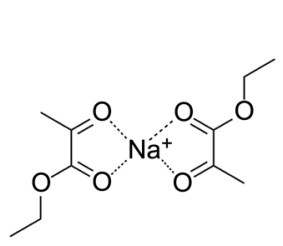

(a)

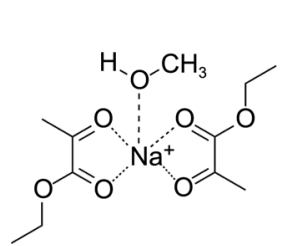

(b)

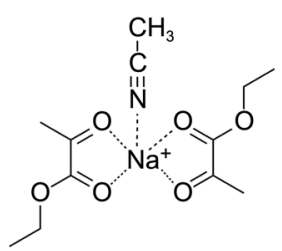

(c)

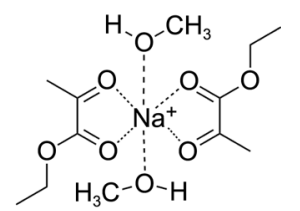

(d)

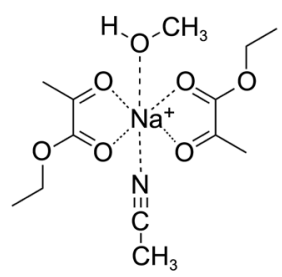

(e)

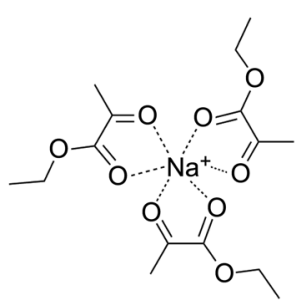

(f)

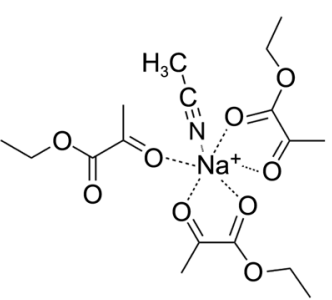

(g)

Figure 1. Adducts detected by positive ESI-MS, consisting of several EP-Na ${ }^{+}$cation complex structures $[\mathrm{m} / z 255$ (A), 287 (B), 296 (C), 319 (D), 328 (E), 371 (F), 412 (G)].

coordination bond and then the construction of several EPcation complexes, as shown in Figure 1. Under the condition of ESI-MS in the positive ion mode, along with pure acetonitrile as a mobile phase, two carbonyl groups in one EP group and one $\mathrm{Na}^{+}$ion are joined to construct a thermodynamically stable, five-membered ring, which eventually generates the dimer of $\mathrm{EP}$ and a sodium adduct $[2 \mathrm{M}+\mathrm{Na}]^{+}$ observed at $\mathrm{m} / \mathrm{z} 255$ (Structure A in Fig. 1) and the trimer of $\mathrm{EP}$ and a sodium adduct $[3 \mathrm{M}+\mathrm{Na}]^{+}$observed at $\mathrm{m} / \mathrm{z} 371$ (Structure F in Fig. 1). In addition, because the $\mathrm{Na}^{+}$ion has five or six coordination sites, one $\mathrm{Na}^{+}$ion is capable of coordinating with extra solvent molecules along with two or three EP groups, depending on the EP concentration or stock solvent. Consequently, we could also detect $\mathrm{m} / \mathrm{z} 296[2 \mathrm{M}+$ $\left.\mathrm{Na}+\mathrm{CH}_{3} \mathrm{CN}\right]^{+}$and $m / z 412\left[3 \mathrm{M}+\mathrm{Na}+\mathrm{CH}_{3} \mathrm{CN}\right]^{+}$which represent the adduct composed of two or three EP groups, a $\mathrm{Na}^{+}$ion, and an acetonitrile molecule (Structure C and G in Fig. 1). Interestingly, when a trace amount of methanol was present in the solvent, an ion peak for $m / z 287[2 \mathrm{M}+\mathrm{Na}+$ $\mathrm{MeOH}]^{+}$was also detected (Structure B in Fig. 1), indicating that the formation of these adducts is more favorable than that of the molecular mass ionized form $[\mathrm{M}+\mathrm{H}]^{+}$in the presence of solvent, and that declustering of the dimer or trimer complex obtained by collisionally induced dissociation in the ESI-MS interface does not take place during the EP analysis. ${ }^{24}$

Based on these results, when pure acetonitrile was used as an eluent for the determination of EP, five different EP adducts were observed with $\mathrm{m} / \mathrm{z} 255,287,296,371$, and 412 which are identified with $[2 \mathrm{M}+\mathrm{Na}]^{+},[2 \mathrm{M}+\mathrm{MeOH}+\mathrm{Na}]^{+}$, $\left[2 \mathrm{M}+\mathrm{Na}+\mathrm{CH}_{3} \mathrm{CN}\right]^{+},[3 \mathrm{M}+\mathrm{Na}]^{+}$, and $\left[3 \mathrm{M}+\mathrm{CH}_{3} \mathrm{CN}+\right.$ $\mathrm{Na}^{+}$, respectively. In addition to these multiple peaks, the elution time was too fast and the linearity of the calibration curve was not adequate $(<0.97)$ in this solvent system. Therefore, we needed to find the optimized solvent condition for HPLC-ESI/MS method to determine and quantify the low concentration of EP in biological media.
Selection of Solvent Compositions for the Chromatographic Condition. Since the selection of mobile phase components is a critical factor for the generation of EP adducts and resolution in HPLC, we have investigated the relationship between EP adducts formation and solvent compositions. Methanol was adapted as a polar solvent along with acetonitrile in our solvent system for the purpose of increasing the elution time. As shown in Figure 2 and Table 1, the formation type of the EP-cation complex and the most intense signal in the mass spectra were affected by variation in the solvent composition of acetonitrile and methanol. First, we examined the effect of the mixed solvent of acetonitrile/methanol $(8 / 2(\mathrm{v} / \mathrm{v}))$ on the pattern of EP adducts formation, and found that there was no significant difference in the pattern between pure acetonitrile and acetonitrile/ methanol $(8 / 2(\mathrm{v} / \mathrm{v}))$ composition. When the solvent ratio was changed into $6 / 4$ and $4 / 6(\mathrm{v} / \mathrm{v})$ of acetonitrile and methanol, five different adducts were generated in the mass spectra with $\mathrm{m} / \mathrm{z} 255,287,296,319$, and 328, where $\mathrm{m} / \mathrm{z} 319$ and 328 were newly formed. The new adducts are identified with $[2 \mathrm{M}+\mathrm{Na}+2 \mathrm{MeOH}]^{+}$and $\left[2 \mathrm{M}+\mathrm{Na}+\mathrm{CH}_{3} \mathrm{CN}+\mathrm{MeOH}\right]^{+}$, respectively. The most intense signal in the $6 / 4(\mathrm{v} / \mathrm{v})$ of acetonitrile/methanol composition was $\mathrm{m} / z 319$ while the most intense signal in the $4 / 6(\mathrm{v} / \mathrm{v})$ of acetonitrile/methanol composition was $\mathrm{m} / \mathrm{z} 296$. In the case of acetonitrile/ methanol ratio of $3 / 7(\mathrm{v} / \mathrm{v})$, five different EP adducts were generated with $\mathrm{m} / \mathrm{z} 255,287,296,371$, and 412 , and the [2M $+\mathrm{Na}+\mathrm{MeOH}]^{+}$adduct $(\mathrm{m} / \mathrm{z} 287)$ was a main peak. When the acetonitrile/methanol ratio was further decreased, interestingly, the peak of $m / z 412$ disappeared at the $2 / 8(\mathrm{v} / \mathrm{v})$ of acetonitrile/methanol composition from the previous peaks while the peak of $m / z 296$ disappeared at both $1 / 9(\mathrm{v} / \mathrm{v})$ of acetonitrile/methanol composition and pure methanol. In the latter cases, among the four peaks of the EP adducts, $\mathrm{m} / \mathrm{z}$ $255,287,371$, and 412 , the relative abundance (\%) of $\mathrm{m} / \mathrm{z}$ $255\left([2 \mathrm{M}+\mathrm{Na}]^{+}\right)$was most intense, which is totally different with other solvent compositions' results. Dependence of 

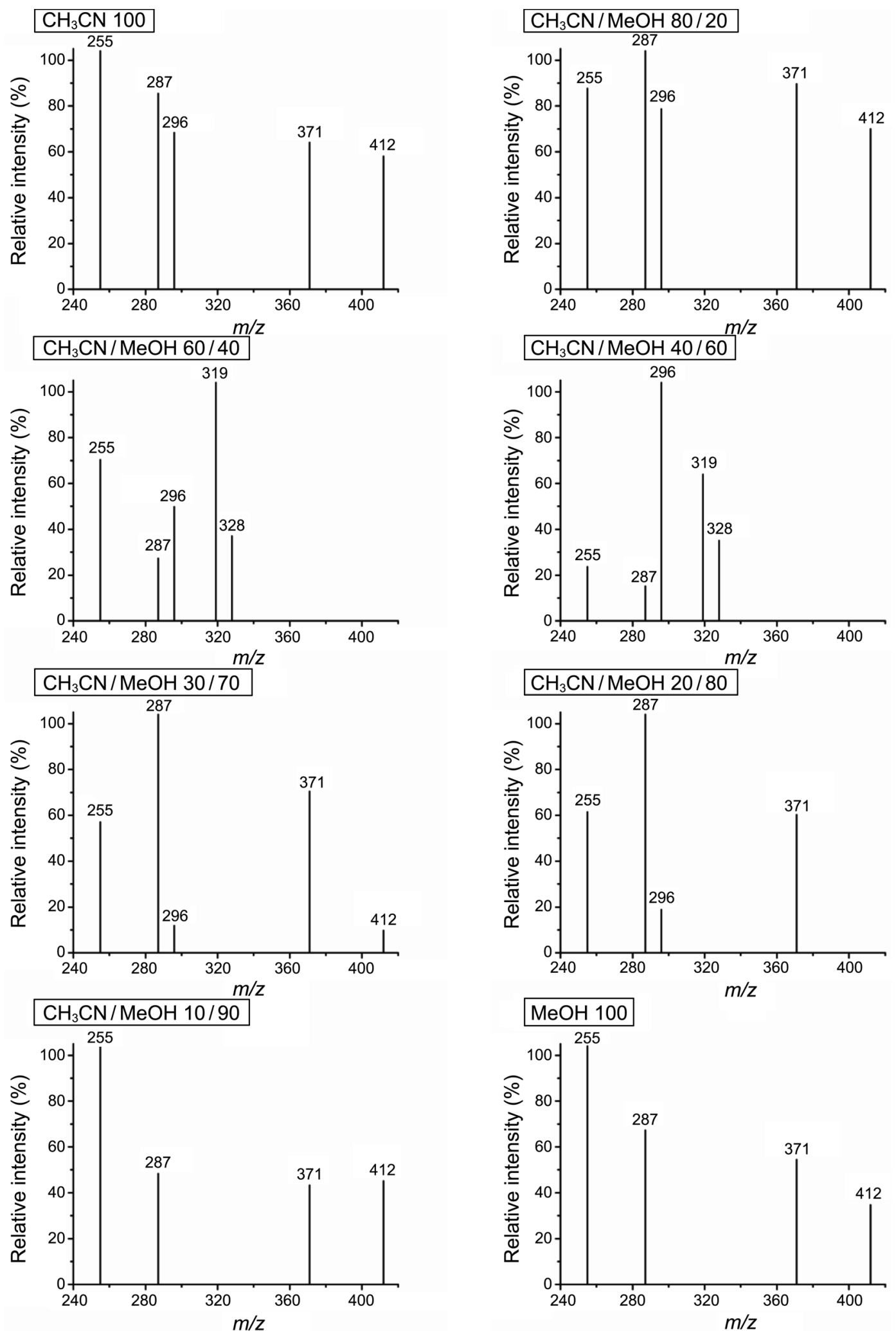

Figure 2. The adduct spectra of EP with sodium ion and solvent at various solvent ratio of acetonitrile/methanol.

different signal appearance and different relative abundance of signals on the solvent compositions can be explained by the fact that the increased hydrogen bonding capacity of methanol molecules allows stabilization of the positive adduct $[2 \mathrm{M}+\mathrm{Na}]^{+}$to a greater degree, which leads to an increase in adjusted abundance values at a acetonitrile/methanol solvent ratio of $1 / 9$ and $0 / 10 \mathrm{v} / \mathrm{v}^{26}$ Since the multiple peaks could complicate the spectral interpretation, the most dominant peak, $m / z 255[2 \mathrm{M}+\mathrm{Na}]^{+}$, was adopted to simplify the data interpretation. Between two solvent compositions of the 
Table 1. EP adducts and relative abundance (\%) of adducts at various solvent ratio of acetonitrile/methanol in the ESI mass spectra $[m=23$ (Na), $\left.32(\mathrm{MeOH}), 41\left(\mathrm{CH}_{3} \mathrm{CN}\right), 116(\mathrm{M})\right]$

\begin{tabular}{|c|c|c|}
\hline $\begin{array}{c}\mathrm{CH}_{3} \mathrm{CN} / \mathrm{MeOH} \\
(\mathrm{v} / \mathrm{v})\end{array}$ & $m / z$ (relative abundance of EP adducts, \% ) & $m / z$ (adducts) \\
\hline $10 / 0$ & $255(100), 287$ (81.5), 296 (64.5), 371 (60.1), 412 (54.1) & \\
\hline $8 / 2$ & 255 (83.8), 287 (100), 296 (74.7), 371 (85.7), 412 (66.0) & \\
\hline $6 / 4$ & 255 (66.4), 287 (23.4), $296(45.8), 319(100), 328(33.0)$ & $255\left(2 \mathrm{M}+\mathrm{Na}^{+}\right), 287\left(2 \mathrm{M}+\mathrm{MeOH}+\mathrm{Na}^{+}\right)$ \\
\hline $4 / 6$ & 255 (19.7), 287 (11.2), 296 (100), 319 (60.0), 328 (31.2) & $296\left(2 \mathrm{M}+\mathrm{CH}_{3} \mathrm{CN}+\mathrm{Na}^{+}\right), 319\left(2 \mathrm{M}+2 \mathrm{MeOH}+\mathrm{Na}^{+}\right)$ \\
\hline $3 / 7$ & 255 (53.2), 287 (100), 296 (7.9), 371 (66.5), 412 (5.73) & $328\left(2 \mathrm{M}+\mathrm{MeOH}+\mathrm{CH}_{3} \mathrm{CN}+\mathrm{Na}^{+}\right), 371\left(3 \mathrm{M}+\mathrm{Na}^{+}\right)$ \\
\hline $2 / 8$ & 255 (57.5), 287 (100), $296(63.3), 371$ (56.3) & $412\left(3 \mathrm{M}+\mathrm{CH}_{3} \mathrm{CN}+\mathrm{Na}^{+}\right)$ \\
\hline $1 / 9$ & 255 (100), 287 (34.3), 371 (43.3), 412 (41.2) & \\
\hline $0 / 10$ & 255 (100), 287 (57.2), 371 (40.6), $412(30.8)$ & \\
\hline
\end{tabular}

acetonitrile/methanol (1/9 v/v) and pure methanol, we observed higher relative abundance of $\mathrm{m} / \mathrm{z} 255$ and lower LOD and LOQ in the acetonitrile/methanol (1/9) condition (LOD 0.1 $\mu \mathrm{g} / \mathrm{mL}$, LOQ $0.5 \mu \mathrm{g} / \mathrm{mL}$ ) than those of pure methanol condition (LOD $0.5 \mu \mathrm{g} / \mathrm{mL}$, LOQ $5.0 \mu \mathrm{g} / \mathrm{mL}$ ). When we ran the same ESI/MS scan mode under the condition of the concentration range of $0.5-60 \mu \mathrm{g} / \mathrm{mL}, 1 / 9(\mathrm{v} / \mathrm{v})$ of acetonitrile $/ \mathrm{meth}$ anol, flow rate $0.05 \mathrm{~mL} / \mathrm{min}$ and SIM mode, the maximum $m / z 255$ peak was obtained. Thus, this condition was used for quantification of EP. Along with this solvent system, the use of short $\mathrm{C}_{8}$ column benefited the retention of the analyte, providing a run time as short as 10 min per sample, because of the difficulty in retaining EP on the $\mathrm{C}_{18}$ column due to its strong polarity. ${ }^{27}$

Selection of Internal Standard (IS). It is necessary to find a proper IS in order to confirm the recovery ratio from the biological media with solvent. For a proper IS, it should 1) be structurally or chemically similar to the analyte, 2) have similar retention to the analyte, 3 ) be well resolved from the analyte, and 4) mimic the analyte in any sample preparation steps. ${ }^{28}$ In this study, DMA was chosen as the IS for the assay because of its similar structure and retention time to those of the analyte (Figs. 3 and 4). Furthermore, because DMA doesn't bind with sodium ion, it didn't compete with EP in generating the sodium adducts.

Linearity and Sensitivity. The calibration range used for the EP analysis was $0.5-60.0 \mu \mathrm{g} / \mathrm{mL}$. The calibration curve was linear across the calibration range without special weighting or curve treatment, and the equation was $\mathrm{Y}=$ 22139.172 X - 18003.202.

The correlation coefficient $\left(r^{2}\right)$ was 0.9979 , which demonstrated the good linearity in the stated concentration range. A typical calibration curve is shown in Figure 5. The LOQ and the $\mathrm{LOD}$ were $0.5 \mu \mathrm{g} / \mathrm{mL}(\mathrm{S} / \mathrm{N}=8)$ and $0.1 \mu \mathrm{g} / \mathrm{mL}(\mathrm{S} / \mathrm{N}=$ $3)$, respectively.

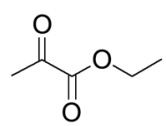

(a)<smiles>CC(=O)N(C)C</smiles>

(b)
Figure 3. Chemical structure of ethyl pyruvate (EP) (A) and $N, N$ dimethylacetamide (DMA) (B). (a)

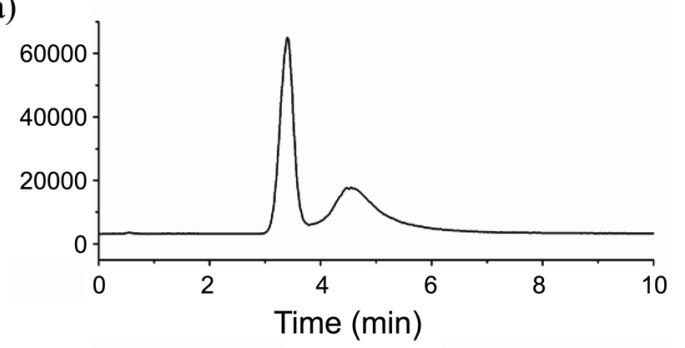

(b)

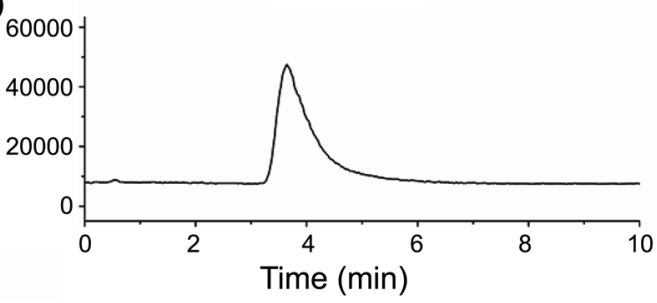

Figure 4. SIM chromatogram of EP (A) and internal standard (IS) (B) dissolved in blank plasma. The retention times of EP $(\mathrm{m} / \mathrm{z} 255)$ and IS ( $\mathrm{m} / \mathrm{z} 88)$ were 3.0-3.8 $\mathrm{min}$ and 3.2-5.0 $\mathrm{min}$, respectively.

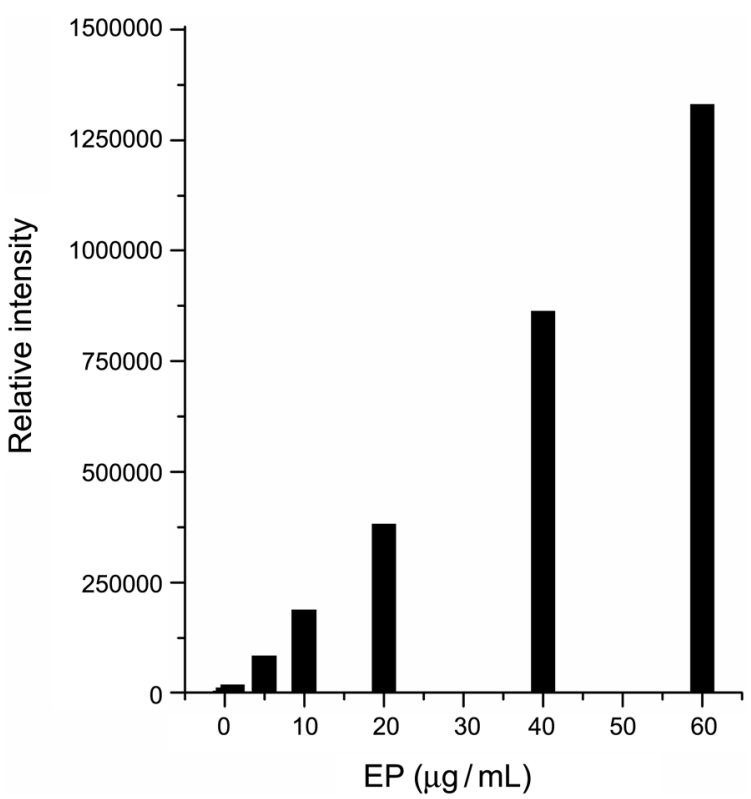

Figure 5. Calibration curve of relative intensity vs. concentration of EP. 
Table 2. Precision (CV, \%) and accuracy (\%) at two concentrations of QC samples (three replicates each day, on three different days)

\begin{tabular}{cccccc}
\hline \multirow{2}{*}{$\begin{array}{c}\text { Spiking } \\
\text { concentration } \\
(\mu \mathrm{g} / \mathrm{mL})\end{array}$} & \multicolumn{2}{c}{ Within-batch $(n=3)$} & & \multicolumn{2}{c}{ Between-batch $(n=3)$} \\
\cline { 2 - 3 } \cline { 6 - 6 } & $\begin{array}{c}\text { Precision } \\
(\mathrm{CV}, \%)\end{array}$ & $\begin{array}{c}\text { Accuracy } \\
(\%)\end{array}$ & & $\begin{array}{c}\text { Precision } \\
(\mathrm{CV}, \%)\end{array}$ & $\begin{array}{c}\text { Accuracy } \\
(\%)\end{array}$ \\
\hline 10 & 1.1 & -6.9 & & 10.8 & -9.3 \\
40 & 1.4 & -0.5 & & 3.6 & 5.3 \\
\hline
\end{tabular}

Table 3. Mean extraction recoveries data of EP in plasma $(n=3)$

\begin{tabular}{ccc}
\hline $\begin{array}{c}\text { Spiked concentration } \\
(\mu \mathrm{g} / \mathrm{mL})\end{array}$ & $\begin{array}{c}\text { Extraction recovery } \\
(\%, \text { mean } \pm \mathrm{SD})\end{array}$ & $\begin{array}{c}\text { RSD } \\
(\%)\end{array}$ \\
\hline 1.0 & $95.8 \pm 3.4$ & 4.7 \\
10.0 & $92.5 \pm 6.8$ & 7.2 \\
40.0 & $93.3 \pm 2.1$ & 3.1 \\
\hline
\end{tabular}

Accuracy and Precision. Table 2 summarizes of the within- and between-batch precision and accuracy at three concentrations. The within-batch precision (expressed as percent relative standard deviation, R.S.D. \%) ranged from 1.1 to $1.4 \%$ and the within-batch accuracy (expressed as percent of nominal values) ranged from 0.5 to $6.9 \%$. The method showed reproducibility with between-batch precision and accuracy ranging from 3.6 to $10.8 \%$ and from 5.3 to $9.3 \%$, respectively. These results demonstrated the satisfactory accuracy, precision and reproducibility of the present method.

Recovery. The extraction recovery of the method was determined by comparing the peak areas obtained from the peak height ratios of the extracted plasma and the original standards. The extraction recovery of EP, evaluated by analyzing three replicates at $1.0,10.0$, and $40.0 \mu \mathrm{g} / \mathrm{mL}$, was $94.8 \pm 2.1 \%$.

Stability. The results for the stability of the EP QC samples are summarized in Table 3. Plasma QC samples $(n=3$ for each of the three concentrations) were stable throughout all three freeze-thaw cycles with percentage errors ranging from 2.3 to $7.5 \%$. QC samples ( $n=3$ for all three concentrations) were also found to be stable for at least $24 \mathrm{~h}$ at room temperature with an error of less than $4.5 \%$ in the calculated concentration compared to the expected concentration. The processed plasma QC samples ( $n=2$ for low and high concentrations) were stable for at least $30 \mathrm{~h}$ after being loaded onto the auto-sampler (error $<3.3 \%$ ). EP stock solutions were stable for at least 3 months in acetonitrile when stored at $-20{ }^{\circ} \mathrm{C}(<5.1 \%$ difference between fresh and test solutions $)$.

Selection of Extraction Method. As EP is a hydrophilic compound, protein precipitation was chosen as the sample preparation method. After several protein precipitants such as ethanol, methanol, and acetonitrile were investigated, acetonitrile was selected as the protein precipitant due to its superior extraction.

Pharmacokinetics Application. This simple, precise, accurate and validated HPLC-ESI/MS method was successfully applied for the pharmacokinetic study of EP in rats after i.v. injection in the tail vein. The mean whole plasma concentration $v s$. time profile for EP following a single bolus

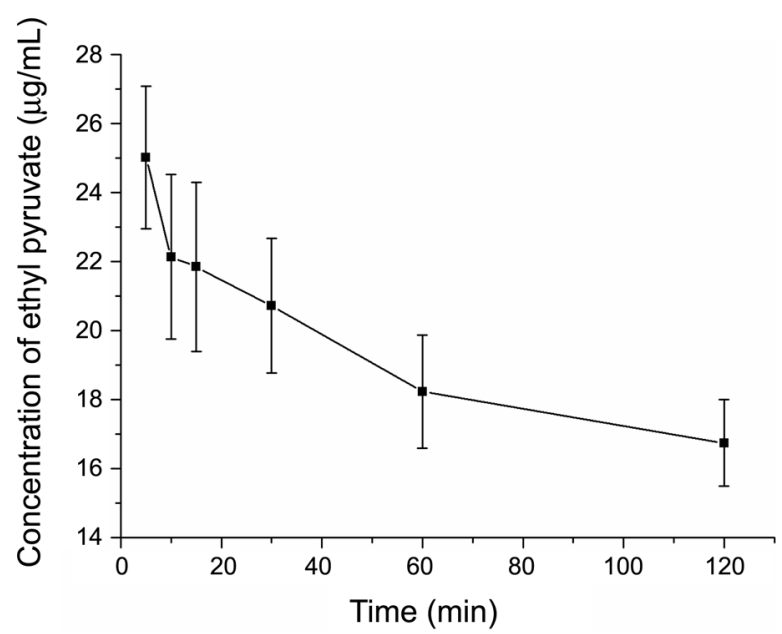

Figure 6. Concentration-time curve of EP in rat plasma after i.v. injection of $50 \mathrm{mg} / \mathrm{kg} \mathrm{EP}$.

dose to an adult male Sprague-Dawley rat is presented in Figure 6. After administration of a single dose of $50 \mathrm{mg} / \mathrm{kg}$ $\mathrm{EP}$, the maximum concentration and time at maximum concentration were $25.01 \mu \mathrm{g} / \mathrm{mL}$ and $5 \mathrm{~min}$ respectively.

\section{Conclusion}

In the absence of any reported LC/MS methods for the determination and quantification of EP in biological media, despite the numerous biological effects of EP, the main aim of this study was to establish such a method. The proposed HPLC-ESI/MS method is the first report of the successful quantification of EP in rat plasma by determining the noncovalent bonded, EP-alkali metal cation complex in biological media. This new method was shown to be simple, highly sensitive, with a lower LOQ of $0.5 \mu \mathrm{g} / \mathrm{mL}$, and linear over a wide range. The use of only a single liquid-liquid extraction step in the sample processing for this method minimizes the sample processing time. Therefore, this simple method can be used for other pharmacokinetic studies of EP in chemical and biological media.

Acknowledgments. This study was supported by the Post Brain Korea 21 program.

\section{References}

1. Varma, S. D.; Devamanoharan, P. S.; Ali, A. H. Free Radical Res. 1998, 28, 131 .

2. Sims, C. A.; Wattanasirichaigoon, S.; Menconi, M. J.; Ajami, A. M.; Fink, M. P. Crit. Care Med. 2001, 29, 1513.

3. Ulloa, L.; Ochani, M.; Yang, H.; Tanovic, M.; Halperin, D.; Yang, R.; Czura, C. J.; Fink, M. P.; Tracey, K. J. Proc. Natl. Acad. Sci. U. S. A. 2002, 99, 12351.

4. Bunger, R.; Mallet, R. T.; Hartman, D. A. Eur. J. Biochem. 1989, 180, 221.

5. Cicalese, L.; Lee, K.; Schraut, W. Am. J. Surg. 1999, 171, 97.

6. Unal, B.; Karabeyoglu, M.; Huner, T.; Canbay, E.; Eroglu, A.; Yildirim, O.; Dolapci, M.; Bilgihan, A.; Cengiz, O. Surgical Innovation 2009, 16, 21. 
7. Sappington, P. L.; Fink, M. E.; Yang, R.; Delude, R. L.; Fink, M. P. Shock 2003, 20, 521.

8. Tawadrous, Z. S.; Delude, R. L.; Fink, M. P. Shock 2002, 17, 473.

9. Venkataraman, R.; Kellum, J. A.; Song, M.; Fink, M. P. Shock 2002, 18, 507.

10. Liu, J.; Segal, M.; Yoo, S.; Yang, G. Y.; Kelly, M.; James, T. L.; Litt, L. Neurochemistry International 2009, 54, 106.

11. Dave, S. H.; Tilstra, J. S.; Matsuoka, K.; Li, F.; DeMarco, R. A.; Beer-Stolz, D.; Sepulveda, A. R.; Fink, M. P.; Lotze, M. T.; Plevy, S. E. Journal of Leukocyte Biology 2009, 86, 633.

12. Liang, X.; Chavez, A.; Schapiro, N. E.; Loughran, P.; Thorne, S. H.; Amoscato, A. A.; Zeh, H. J.; Beer-Stolz, D.; Lotze, M. T.; Vera, M. E. Journal of Leukocyte Biology 2009, 86, 599

13. Han, Y.; Englert, J. A.; Yang, R.; Delude, R. L.; Fink, M. P. The Journal of Pharmacology and Experimental Therapeutics 2005, 312, 1097.

14. Lee, J. Y.; Lee, J. Y.; Lee, S. E. Invest Ophthalmol. Vis. Sci. 2004, $45,1523$.

15. Rsung, A.; Kaizu, T.; Nakao, A. Transplantation 2005, 27, 196.

16. Varma, S. D.; Devamanoharan, P. S.; Ali, A. H. Free Rad. Res. 2000, 33, 23 .
17. Cho, I. H.; Kim, S. Y.; Kim, J. B.; Kim, T. K.; Lee, K. W.; Han, P. L.; Lee, J. K. J. of Neuroscience Research 2006, 84, 1505.

18. Yu, Y. M.; Kim, J. B.; Lee, K. W.; Kim, S. Y.; Han, P. L.; Lee, J. K. Stroke 2005, 36, 2238.

19. Shimizu, C.; Nara, Y.; Takashio, M. J. Am. Soc. Brew. Chem. 2005, 63, 135.

20. Bartók, M.; Bartók, T.; Szöllösi, G.; Felföldi, K. J. Mass Spectrom. 2002, 37, 1034.

21. Bartók, M.; Kele, Z.; Körtvélyesi, T.; Bartók, T.; Felföldi, K. Rapid Commun. Mass Spectrom. 2003, 17, 2849.

22. Bartók, M.; Szabó, P. T.; Bartók, T.; Szöllösi, G. Rapid Commun Mass Spectrom. 2000, 14, 509.

23. Saraiva, M. A.; Borges, C. M.; Florêncio, M. H. J. Mass Spectrom. 2006, 41, 216.

24. Kebarle, P. J. Mass Spectrom. 1997, 32, 922.

25. Loo, J. A. Int. J. Mass Spectrom. 2000, 200, 175.

26. Emmert, J.; Pfluger, M.; Wahl, F. LC.GC Europe 2004, 17, 646.

27. Zhang, D.; Du, X.; Liu, M.; Li, H.; Jing, Y.; Zhao, L.; Gu, J. J. Chromatogr. B 2008, 863, 223.

28. Snyder, L. R.; Kirkland, J. J.; Glach, J. L. Practical HPLC Method Development; John Wiley \& Sons Inc.: New York, 1997; p 659. 